\title{
Awareness of Obstetric Fistula and Associated Factors Among Women in Reproductive Age Group Attending Public Hospitals, llubabor Zone, Oromia Regional State, South West Ethiopia, 2021
}

Dessalegn Nigatu Rundasa

MeU: Mettu University

Tarekegn Fekede Wolde ( $\square$ fekedetarekegn88@gmail.com )

MeU: Mettu University https://orcid.org/0000-0003-2464-7151

Kenbon Bayisa Ayana

Mettu university https://orcid.org/0000-0003-0329-9389

Abeya Fufa Worke

MeU: Mettu University

\section{Research Article}

Keywords: Obstetric fistula, Reproductive Age Group, Public Hospitals, Oromia Regional State, South West Ethiopia, llubabor Zone

Posted Date: June 8th, 2021

DOI: https://doi.org/10.21203/rs.3.rs-578279/v1

License: (c) (1) This work is licensed under a Creative Commons Attribution 4.0 International License.

Read Full License 


\section{Abstract}

Background: Obstetric fistula occurs in all developing countries but it is confined to the "fistula belt" across the northern half of Sub-Saharan Africa from Mauritania to Eritrea and in the developing countries of the Middle East and Asia. Ending obstetric fistula is critical to achieving the Sustainable Development by 2030 . So creating awareness on obstetrics fistula among women in reproductive age group have crucial role in reducing morbidity, mortality and social stigma.

Objective: To assess awareness on obstetric fistula and its associated factors among reproductive age women attending governmental hospitals in llubabor zone, Oromia region, Ethiopia, 2021.

Methods: Institutional based cross-sectional study design was conducted. The sample size was estimated by using a single population proportion formula. The collected data was coded and entered to Epi data version 3.1 then exported to SPSS version 24 for descriptive and inferential analysis. Adjusted odds ratio (AOR) along with 95\% confidence level was estimated to assess the strength of the association and a $\mathrm{p}$ value $<0.05$ was considered to declare the statistical significance in the multivariable analysis in this study.

Result: In this study a total of 400 clients were participated in the study. The mean ages of participants were $30.26(S D \pm 8.525)$ years old. Education of women's who cannot read and write are $85 \%$ less likely to have good awareness than women who are above secondary level of education (AOR=0.162:95\% Cl (0.081-0.364)). While Women's who have primary education level are $83 \%$ less likely to have good awareness than women who are above secondary level of education (AOR $=0.170: 95 \% \mathrm{Cl}(0.085-$ 0.446)).In addition, my study shows women's who haven't heard about obstetric complication are $54 \%$ less likely to have awareness on obstetric fistula than those who heard about obstetric complication (AOR=0.458:95\% Cl (0.368-0.643).

Conclusion: This study identifies that, educational level of women, history of pregnancy, distance to the nearby health institution and awareness on obstetrics complications were the factors associated with awareness of reproductive age women on obstetrics fistula. Hence, increasing awareness on obstetric fistula plays a key role to avert this problem.

\section{Plain Language Summary}

Globally, between 2-3 million women were affected by obstetric fistula. Moreover, obstetric fistula is common in developing nations, as around $60 \%$ of it was found in sub-Saharan the so called 'fistula belt' and middle east Asia. This devastating condition adversely affects both Physical and Mental health of the women. There is a little research conducted concerning the health burdens of the obstetric fistula in southwest, Ethiopia. Therefore, this article provides the better understanding of level of awareness on obstetric fistula and barrier (factors) that hinders the early detection and treatment of obstetric fistula. 
In this study, cross-sectional study design was employed and data were collected from 400 women's of reproductive age group who visited public hospitals ion Ilu Aba Bor Zone. Our study shows that educational status, hasn't heard about complication of obstetric fistula, far distant from health facility and not being pregnant were found to be factors that hinder the early detection and management of obstetric fistula. In conclusion, the finding of this study reported a low magnitude of level of awareness on obstetric fistula as compared to other previous studies.

\section{Introduction}

Vaginal Fistula is abnormal communication between vagina and adjacent tubular structures-usually bladder and rectum -leading to continuous leakage of urine or faeces- through vagina (1). Globally, an estimated 50,000 to 100,000 women develop fistula annually and about 2 million women currently live with fistula, which is burden in almost 60 countries. Moreover, obstetric fistula appears in all developing countries, including African and middle east Asia, particularly confined across northern half of subSaharan Africa from Mauritania to Eritrea as called 'Fistula belt'(2). In Africa, Fistula predominantly caused by prolonged and or obstructed labor; however, abdominal hysterectomy remains the most common cause of vaginal fistula in developed countries (3). Currently, in Ethiopia there are more than 110,000 women have vaginal fistula, of those less than 2000 women get treatment in the last 3years(4). Despite the fact that, Obstetric fistula is an indicator of health system failing to provide accessible, timely and appropriate intrapartum care(5). Moreover, Obstetric fistula is devastating lifelong morbidity if left untreated, with severe medical, social, psychological and economic consequences (4),(6),(7), (8). The underlying factors contributing to Obstetrics fistula including no skilled birth attendants(9),(10), poor health - seeking behavior, poor referral system and transportation(11),(12) network (11),(13), age and physical maturity(12), (14), (15),(16), iatrogenic surgical damage(9), Educational status((10), (17), (18), sexual violence(16), poverty(11),(13), lack of awareness(5),(12),(15), (19) and not spacing between child births(9). Despite these contributing factors, the main reason why women preventing from Fistula care was due to lack of awareness on obstetric fistula prevention and treatment takes a lion share(6)and lack of awareness is a leading reason to seeking treatment(7). Therefore, identify awareness and associated factors to have paramount importance to avert and or to reduce obstetric fistula among women of reproductive age categories. So that, measuring awareness and factors associated on obstetric fistula among women of reproductive age in llu Aba Bor zone health facility is important as there is scares information in study setting.

\section{Methods And Materials}

\section{Study area and setting}

The study area was public hospitals in llu Aba Bor zone. This is one of Oromia regional state zone which is located $600 \mathrm{~km}$ away from the capital city, Addis Ababa, Ethiopia. It is bordered on the south by the south nation, nationality and Peoples', on the southwest by the Gambela , on the west by kelem wollega zone, on the north by west wollega zone, on the northwest by East wollega zone, and on the east by 
Jimma zone. The zone has an estimated area of 15,135.33 $\mathrm{KM}^{2}$. Moreover, the zone has two hospitals and thirty nine health centers. We used the two hospitals (Mettu Karl Referral hospital \& Darimu district Hospital)

\section{Study design and period}

An Institution based cross-sectional study design was used to from September 20 to Nov.31, 2021.

\section{Source and study population}

All women in reproductive age group attending governmental hospitals in llubabor zone visiting Gynecology OPD and ANC.

\section{Study unit}

Randomly selected reproductive age women and fulfill the inclusion criteria.

\section{Eligiblity criteria}

\section{Inclusion criteria}

All reproductive age group women those available at the time of data collection period, and who are visiting Gynecology OPD and ANC.

\section{Sample size determination}

The sample size was estimated by using a single population proportion formula. By considering the prevalence level of obstetric fistula that can estimate maximum sample size (57.8\%), marginal error (d) 0.05 , with $95 \%$ confidence interval certainty and margin of error 0.05 was considered. Finally, by adjusting $10 \%$ non-respondent rate the sample size turned out 413 .

\section{Sampling procedure}

Mettu Karl Referral and Darimu district Hospitals were selected. Simple random sampling technique was employed after study subjects was proportionally allocated to each hospitals

\section{Operational definitions}

Awareness: Conscious or informed about obstetric fistula cause, prevention and presentation.

Good Awareness: Participants who scored above mean score whereas, Poor Awareness participants who scored less than the mean.

\section{Data collection tool and technique}


A structured interviewer administered adopted questionnaire was used for data collection. The questionnaire was first prepared in English and then translated in to the local naïve language 'Afan Oromo' and re-translated back into English to maintain consistency by fluent bilingual expert. Data were collected from each study subjects by face-to-face interview using structured questionnaire, which is prepared in local language Afan Oromo

\section{Data quality control}

A two days training was given for both data collectors and supervisors on data collection procedure, accuracy and completeness of the data. After the training, pretest was carried out on the $5 \%$ of the sample was done in similar population that was in other health facility, to ensure the quality and validity of the data. Regularly, the supervisor checked for completeness. The collected data were reviewed and checked for completeness before data entry.

\section{Data processing and analysis}

Data were checked for completeness, clarity and consistency. The data were entered into Epi data version 3.1 and exported to SPSS version 24 statistical software for analysis. Descriptive statistics were employed. Logistic regression was used to see the association between dependent and independent variable. Statistical significance was declared at P-value less than 0.05 at $95 \% \mathrm{Cl}$ as cut of point. Odds Ratio at $95 \% \mathrm{Cl}$ was used to identify the presence and strength of association.

\section{Results}

\section{Socio-Demographic Factors}

A total of 400 respondents were participated, with the response rate of $94.8 \%$. The mean age of participants was 30.26 (SD \pm 8.525 ) years old. More than half $(55 \%)$ of participants were Orthodox Christian in religion. Majority of participants were Oromo in ethnicity. (Table 1) 
Table 1

Socio demographic characteristics of participants among women in reproductive age group attending governmental hospitals in llubabor zone, Oromia regional state, south west Ethiopia,2021 ( $n=400)$.

\begin{tabular}{|lll|}
\hline Variable & Frequency & Percent \\
\hline Age & & \\
\hline$<$ mean(30.26 years) & 208 & 52 \\
>mean(30.26 years) & 192 & 48 \\
\hline Religion & & \\
\hline Orthodox Christian & 220 & 55.0 \\
\hline Muslim & 133 & 33.3 \\
\hline Catholic & 12 & 3 \\
\hline Protestant & 35 & 8.8 \\
\hline Ethnicity & & \\
\hline Oromo & 256 & 64 \\
\hline Amhara & 98 & 24.5 \\
\hline Gurage & 29 & 7.3 \\
\hline Others & 17 & 4.3 \\
\hline
\end{tabular}

Socio demographic characteristics of participants among women in reproductive age group attending governmental hospitals in llubabor zone, Oromia regional state, south west Ethiopia,2021 $(n=400)$ (Table 1 continued) 


\begin{tabular}{|c|c|c|}
\hline \multicolumn{3}{|l|}{ Marital Status } \\
\hline Single & 100 & 25 \\
\hline Married & 254 & 63.5 \\
\hline Divorced & 20 & 5 \\
\hline Separated & 11 & 2.8 \\
\hline Widowed & 15 & 3.8 \\
\hline \multicolumn{3}{|l|}{ Marriage Age } \\
\hline $15-19$ & 112 & 28 \\
\hline $20-24$ & 142 & 35.5 \\
\hline $25-29$ & 26 & 6.5 \\
\hline $30-34$ & 5 & 1.3 \\
\hline $35-39$ & 1 & 0.3 \\
\hline Educational level & 89 & 22.3 \\
\hline Can't read and write & 104 & 26 \\
\hline Primary education & 112 & 28 \\
\hline Secondary education & 95 & 23.8 \\
\hline \multicolumn{3}{|l|}{ Above secondary } \\
\hline \multicolumn{3}{|l|}{ Occupation } \\
\hline House wife & 193 & 48.3 \\
\hline Student & 65 & 16.3 \\
\hline Farmer & 9 & 2.3 \\
\hline Merchant & 42 & 10.5 \\
\hline Government employee & 40 & 10 \\
\hline Private employee & 51 & 12.8 \\
\hline \multicolumn{3}{|l|}{ Monthly Income } \\
\hline Less than 1000 & 167 & 41.8 \\
\hline $1001-2000$ & 129 & 32.3 \\
\hline $2001-3000$ & 54 & 13.5 \\
\hline $3001-4000$ & 25 & 6.3 \\
\hline
\end{tabular}




\begin{tabular}{|lll|}
\hline Marital Status & & \\
\hline $4001-5000$ & 25 & 6.3 \\
\hline
\end{tabular}

\section{Obstetrics Characteristics}

Out of total, 205(51.1\%) participants don't hear about obstetrical complication. Half of the participants $(49.8 \%)$ use modern FP methods. Women's who have less than three pregnancies are 170 (42.5\%) (Table 2). 
Table 2

Obstetric characteristics of participants among women in reproductive age group attending governmental hospitals in Ilu Aba Bor zone, Oromia regional state, south west, Ethiopia, 2021.

\begin{tabular}{|c|c|c|}
\hline Variable & Frequency & Percent \\
\hline \multicolumn{3}{|c|}{ Heard about obstetric complication } \\
\hline Yes & 195 & 48.9 \\
\hline No & 205 & 51.1 \\
\hline \multicolumn{3}{|c|}{ History of induced abortion $(n=285)$} \\
\hline Yes & 62 & 21.8 \\
\hline No & 223 & 78.2 \\
\hline \multicolumn{3}{|c|}{ History of birth complication $(n=285)$} \\
\hline Yes & 122 & 42.8 \\
\hline No & 163 & 57.2 \\
\hline \multicolumn{3}{|c|}{ Contraceptive use } \\
\hline Yes & 197 & 49.3 \\
\hline No & 203 & 50.8 \\
\hline \multicolumn{3}{|c|}{ Type of contraceptive used $(n=197)$} \\
\hline Injectable & 106 & 53.8 \\
\hline Pills & 41 & 20.8 \\
\hline Implants & 35 & 17.8 \\
\hline IUCD & 12 & 6.1 \\
\hline Condom & 3 & 1.5 \\
\hline \multicolumn{3}{|c|}{ Have you ever en pregnant } \\
\hline Yes & 253 & 63.3 \\
\hline No & 147 & 36.8 \\
\hline \multicolumn{3}{|c|}{ Age at 1st Pregnancy } \\
\hline 15-19 & 112 & 39.2 \\
\hline $20-24$ & 142 & 49.7 \\
\hline $25-29$ & 26 & 9.1 \\
\hline $30-34$ & 5 & 1.7 \\
\hline
\end{tabular}




\begin{tabular}{|lll|}
\hline Variable & Frequency & Percent \\
\hline $35-39$ & 1 & 0.3 \\
\hline Number of Pregnancy & & \\
$1-3$ & 170 & 42.5 \\
$4-6$ & 90 & 22.5 \\
$7-9$ & 21 & 5.3 \\
$10-12$ & 4 & 1.0 \\
\hline
\end{tabular}

\section{Awareness on Obstetric fistula}

Women's who have ever heard of obstetric fistula are $53 \%$ and out of these, $34.6 \%$ of women get information from media about obstetric fistula. Moreover, $38.1 \%$ of them reported inability to control urine as symptom of obstetric fistula (Table 4). 
Table 4

Participants characteristics about Awareness on Obstetric fistula among women in reproductive age group attending governmental hospitals in llu Aba Bor zone, Oromia regional state, south west Ethiopia, 2021

\begin{tabular}{|lll|}
\hline Variable & Frequency & Percent \\
\hline Ever heard about obstetric fistula & & \\
\hline Yes & 212 & 53 \\
\hline No & 188 & 47 \\
\hline Symptoms of obstetric fistula you heard & & \\
\hline Unable to control urine & 82 & 38.1 \\
\hline Unable to control feces & 4 & 1.9 \\
\hline Unable to control urine and feces & 58 & 27 \\
\hline Bleeding and pain during sex & 23 & 10.7 \\
\hline Abnormal Vaginal discharge & 23 & 10.7 \\
\hline Irritation during urination & 25 & 11.6 \\
\hline Source of information about obstetric & & \\
\hline Fistula & & 26.2 \\
\hline Health facility & 56 & 22 \\
\hline Family and friends & 47 & 7 \\
\hline School & 15 & 34.6 \\
\hline Media & 74 & 10.3 \\
\hline Victim of fistula & 22 & \\
\hline
\end{tabular}

Women's who have good awareness on cause, symptom and preventions are 177(44.3\%), 219(54.8\%) and $177(44.3 \%)$ respectively. General Obstetric fistula awareness of women's in visiting hospitals in llu Aba Bor zone is $50 \%$ which have good awareness on obstetric fistula. (Fig. 3).

\section{Factors associated with awareness status on obstetric fistula}

In Bivariate analysis the result shows Educational status of women, distance to health center, modern contraceptive use, hearing about delivery complication and history of pregnancy were found to have significant association.

In Multivariate analysis the result showed a significant association tween history of pregnancy and the odds of having good awareness. Those reproductive age group who had history of pregnancy were $68 \%$ 
less likely to have good awareness on obstetrics fistula prevention than their counter parts (AOR = $0.399: 95 \% \mathrm{Cl}(0.241-0.661))$. distance to the nearby health institution(hospital), those who lived above half an hour foot distance were $65 \%$ less likely to have good awareness than those living near to health facility (AOR $=0.355: 95 \% \mathrm{Cl}(0.212-0.594)$ ). Education of women's who cannot read and write are $85 \%$ less likely to have good awareness than women who are above secondary level of education.(AOR = $0.162: 95 \% \mathrm{Cl}(0.081-0.364))$. Women's who have primary education level are $83 \%$ less likely to have good awareness than women who are above secondary level of education (AOR $=0.170: 95 \% \mathrm{Cl}(0.085-$ 0.446)) and women's who have secondary education level are $70 \%$ less likely to have good awareness than women who are above secondary level of education ( $A O R=0.299: 95 \% \mathrm{Cl}(0.153-0.584)$ ) In addition, my study shows women's who haven't heard about obstetric complication are $54 \%$ less likely to have awareness on obstetric fistula than those who heard about obstetric complication (AOR $=0.458: 95 \% \mathrm{Cl}$ $(0.368-0.643))$. (Table 5) 
Table 5

Multivariate analysis showing the impact of selected associated factors of obstetric fistula among reproductive age women in in public hospitals in llu Aba Bor zone, Oromia Region, south west Ethiopia, 2021.

\begin{tabular}{|c|c|c|c|c|c|}
\hline \multirow[b]{2}{*}{ Variable } & \multicolumn{5}{|c|}{ Awareness on OF } \\
\hline & Good & Poor & COR(95\% Cl) & AOR(95\% Cl) & $P$ value \\
\hline \multicolumn{6}{|l|}{ Women education } \\
\hline Can't read and write & $30(33.7 \%)$ & $59(66.3 \%)$ & $\begin{array}{l}0.119(0.060- \\
0.234)\end{array}$ & $\begin{array}{l}0.162(0.081- \\
0.364)\end{array}$ & $0.000 * *$ \\
\hline Primary & 41(39.4\%) & $63(60.6 \%)$ & $\begin{array}{l}0.152(0.080- \\
0.290)\end{array}$ & $\begin{array}{l}0.170(0.085- \\
0.446)\end{array}$ & $0.001 *$ \\
\hline Secondary & $52(46.4 \%)$ & $60(53.6 \%)$ & $\begin{array}{l}0.203(0.108- \\
0.382\end{array}$ & $\begin{array}{l}0.299(0.153- \\
0.584)\end{array}$ & $0.000 * *$ \\
\hline Above secondary & 77(81.1\%) & $18(18.9 \%)$ & 1 & & \\
\hline \multicolumn{6}{|l|}{ HDC } \\
\hline No & 81(39.7\%) & $123(60.3 \%)$ & $\begin{array}{l}0.430(0.288- \\
0.642)\end{array}$ & $\begin{array}{l}0.458(0.368- \\
0.678)\end{array}$ & $0.000 * *$ \\
\hline Yes & $118(60.5 \%)$ & 77(39.5\%) & 1 & 1 & \\
\hline \multicolumn{6}{|c|}{$\begin{array}{l}\text { Distance to HF on foot } \\
\text { by minutes }\end{array}$} \\
\hline$>30$ & $36(26.5 \%)$ & $100(73.5 \%)$ & $\begin{array}{l}0.220(0.139- \\
0.346)\end{array}$ & $\begin{array}{l}0.355(0.212- \\
0.594)\end{array}$ & $0.000 * *$ \\
\hline$\leq 30$ & $164(62.3 \%)$ & 100(37.7\%) & 1 & 1 & \\
\hline \multicolumn{6}{|l|}{ Contraceptive use } \\
\hline No & $91(44.8 \%)$ & $112(55.2 \%)$ & $\begin{array}{l}0.656(0.442- \\
0.973)\end{array}$ & $\begin{array}{l}1.101(0.601- \\
2.013)\end{array}$ & 0.712 \\
\hline Yes & $109(55.3 \%)$ & $88(44.7 \%)$ & 1 & 1 & \\
\hline \multicolumn{6}{|l|}{ Ever pregnancy } \\
\hline No & $46(31.3 \%)$ & $101(68.7 \%)$ & $\begin{array}{l}0.293(0.190- \\
0.450)\end{array}$ & $\begin{array}{l}0.399(0.241- \\
0.661)\end{array}$ & $0.002^{*}$ \\
\hline Yes & $154(60.9 \%)$ & $99(39.1 \%)$ & 1 & 1 & \\
\hline \multicolumn{6}{|c|}{ OF: Obstetric-Fistula, HF: Health Facility, HDC: Heard Delivery Complication } \\
\hline
\end{tabular}

\section{Discussion}


In this study, half of respondents (50\%) (95\%) confidence interval (34.62-45.37) have had good awareness about obstetric fistula. despite the problems associated with obstetric fistula, many women are not aware of the obstetric fistula. It may difficult to control a disease that people are not aware of. This finding may also imply that these women were not aware of how to prevent obstetric fistula. This finding was lower when compared with the study done in Delanta district which is $55.4 \%$ the difference might due to sample size and study participants. Our finding was consistent when compared to a study done in Ghana which was $47.6 \%$ (15).

This study showed that $212(53 \%)$ reproductive age group women have heard obstetric fistula this result is higher than EDHS, 2016 of which 2 in 5 women interviewed in the survey had heard of obstetric fistula (39\%) (20). This difference might be due to EDHS takes sample from different regions of Ethiopia which have different geographical location, social and cultural factors and my study took only participants who visit hospitals.

My study shows there is significant association between women awareness and their educational level, women's who cannot read and write are $84 \%$ less likely to have good awareness than women who are above secondary level of education. $(\mathrm{AOR}=0.162: 95 \% \mathrm{Cl}(0.081-0.364))$. Women's who have primary education level are $83 \%$ less likely to have good awareness than women who are above secondary level of education $(A O R=0.170: 95 \% \mathrm{Cl}(0.085-0.446))$ and women's who have secondary education level are $70 \%$ less likely to have good awareness than women who are above secondary level of education (AOR = $0.299: 95 \% \mathrm{Cl}(0.153-0.584))$. This shows that when education level is improved the awareness comes more improved. The finding also supported by study conducted in Cameroonian women which shows53 $\%$ of women who had no previous knowledge on obstetric fistula were generally the illiterate (8). Another study, which supports my study, is survey on obstetric fistula awareness which was done in Northern Ghana, how that Level of education of the participants had a significant influence on

Awareness the level of fistula with about $50.2 \%$ those with higher education aware of as Compared to $49.8 \%$ who had no knowledge about fistula the result of this study showed that there were a significant association tween women's awareness and distance to the nearby health center. Women living in areas where hospital or health institution is found at a distance more than half an hour(on foot) from the home they are living, their awareness is $65 \%$ less likely to good than those living in areas which are found at a distance less than or equal to half an hour. $(\mathrm{AOR}=0.355: 95 \% \mathrm{Cl}(0.212-0.594))$. This can supported by studies in Ethiopia that identifies distance to the health care facility was linked with poor knowledge related to fistula and poor health seeking behavior which increases the likelihood of more fistula cases (21).A study on awareness to health knowledge in Western China showed that health knowledge declined as the distance from the nearby health institution increases (AOR:0.144, $p=0.002$ ) (22). This might cause of , as the health facility comes near women's are to visit the facility cause they don't need transportation.

In my study women's who haven't heard about obstetric complication are $54 \%$ less likely to have awareness on obstetric fistula than those who heard about obstetric complication (AOR $=0.458: 95 \% \mathrm{Cl}$ (0.368-0.643)). This finding is supported by study done in Amhara region which shows the presence of 
awareness about complications of delivery other than obstetrics fistula was significantly associated with sufficient knowledge on obstetrics fistula (AOR $=0.498: 95 \% \mathrm{Cl}(0.317-0.783)$. This might cause of the issue that obstetrics fistula can also informed together with dangers of pregnancy since it is among the child birth complications.

This study showed that good awareness on obstetric fistula tended to more common among women with previous pregnancy history than those without. Those who had history of pregnancy were $60 \%$ less likely to have good awareness (AOR $=0.399: 95 \% \mathrm{Cl}(0.241-0.661)$ ). This finding is supported by study done in Delanta district which shows, women with no pregnancy history were $87 \%$ times less likely to have sufficient knowledge. The finding is also consistent with other studies which showed non-exposure to pregnancy prevents women's knowledge on obstetrics fistula by $80 \%$ (16).

\section{Conclusion}

The finding indicates that $50 \%$ of reproductive age women have poor awareness about obstetric fistula, and Educational level of women, history of pregnancy, distance from health facility and awareness on obstetrics complications were the factors associated with awareness of reproductive age women on obstetrics fistula. Hence, giving a due attention that targets the reproductive health of women in this study area is critical.

\section{Limitations}

There might be recall bias, cross sectional study; it cannot show cause-effect relationship tween the variables studied and the same to other behavioral studies, respondents might not reply openly to sensitive and private questions.

\section{Abbreviation And Acronyms}

CS: Caesarean Section, EDHS: Ethiopian Demographic and Health Survey, DH: Darimu hospital, FGD: Focused Group Discussions, IDI: In-depth Interviews, IRB: Institutional Review Board, OF: Obstetric Fistula, MKH: Mettu Karl Hospital, RVF: Recto Vaginal Fistula, SPSS: Statically Package for Social Sciences, TBA: Traditional Birth Attendants, UNFPA: United Nation Fund for Population Agency, USAID: United States Agency for International Developments, VVF: Vesico-vaginal Fistula.

\section{Declarations}

\section{Ethical Approval}

To conduct the study an ethical approval was obtained from IRB of College of Health Sciences, Mettu University. Official letter of cooperation was written to llu Aba Bor zonal health bureau from department of public health. Written, informed and signed consent was taken from respondents of age 18 and above after telling, the confidentiality was kept and the role of their participation is for research purpose. 


\section{Conflict of Interest}

The authors declare that they have no competing of interest.

\section{Funding}

Not applicable

\section{Availability of data and materials}

All data supporting our findings will be shared upon request.

\section{Consent for publications}

Not applicable

\section{Ethics approval and Consent to participate}

Not Applicable

\section{Authors' Contributions}

$T F, D N, K B$ and $A F$ inception designed the proposal, data analysis, interpretation, manuscript draft, revised the manuscript and wrote the paper. TF and DN participate in data collection and entry. KB and AF participate in analysis. All Authors read and approved the final paper.

\section{Acknowledgement}

We are thankful to the Collage of Health Sciences, Mettu University, for sponsoring the project. We would like to the llu Aba Bor health bureau to permitting us to conduct the study and providing the preliminary information. Lastly, we would like to extend thanks to study participants, supervisors, and data collectors.

\section{References}

1. Disease Control Priorities, Third Edition (Volume 1): Essential Surgery. Dis Control Priorities [Internet]. [cited 2021 May 11]; Available from: https://elibrary.worldbank.org/doi/pdf/10.1596/978-1-46480346-8

2. Treuthart MP. No Woman, No Cry - Ending the War on Women Worldwide and the International Vlolence against Women Act (I-VAWA). Boston Univ Int Law J. 2015;33:73.

3. Miller EA, Webster GD. Current management of vesicovaginal fistulae. Curr Opin Urol. 2001 Jul;11(4):417-21.

4. Maheu-Giroux M, Filippi V, Samadoulougou S, Castro MC, Maulet N, Meda N, et al. Prevalence of symptoms of vaginal fistula in 19 sub-Saharan Africa countries: a meta-analysis of national household survey data. Lancet Glob Health. 2015 May 1;3(5):e271-8. 
5. SciELO - Public Health - Measuring the incidence and prevalence of obstetric fistula: approaches, needs and recommendations Measuring the incidence and prevalence of obstetric fistula: approaches, needs and recommendations [Internet]. [cited 2021 May 14]. Available from: https://www.scielosp.org/article/bwho/2015.v93n1/60-62/en/

6. Baker Z, Bellows B, Bach R, Warren C. Barriers to obstetric fistula treatment in low-income countries: a systematic review. Trop Med Int Health. 2017;22(8):938-59.

7. Causes and consequences of obstetric fistula in Ethiopia: A literature review-Indian Journals [Internet]. [cited 2021 May 21]. Available from: https://www.indianjournals.com/ijor.aspx? target=ijor:ijmrhs\&volume=2\&issue $=2 \&$ article $=024$

8. Trajectories of women's physical and psychosocial health following obstetric fistula repair in Uganda: a longitudinal study [Internet]. [cited 2021 May 21]. Available from: https://onlinelibrary.wiley.com/doi/epdf/10.1111/tmi.13178

9. den Hollander GC, Janszen EWM. Obstetric fistulas in Uganda: scoping review using a determinant of health approach to provide a framework for health policy improvement. BMC Pregnancy Childbirth. 2020 Dec;20(1):257.

10. Profile and outcome of patients with recurrent urogenital fistula in a fistula centre in Nigeria | SpringerLink [Internet]. [cited 2021 May 21]. Available from: https://link.springer.com/article/10.1007/s00192-018-3738-8

11. Swain D, Parida SP, Jena SK, Das M, Das H. Prevalence and risk factors of obstetric fistula: implementation of a need-based preventive action plan in a South-eastern rural community of India. BMC Womens Health. 2020 Dec;20(1):40.

12. Balcha WF, Nigussie AA, Beyene FY, Tesfu AA. Awareness and Its Associated Factors of Obstetrics Fistula among Antenatal Care Attendees in Injibara Town Health Institutions, Awi Zone, North West, Ethiopia, 2019. J Pregnancy. 2020 Jul 1;2020:1-7.

13. A review of surgical procedures to repair obstetric fistula - Pope - 2020 - International Journal of Gynecology \&amp; Obstetrics - Wiley Online Library [Internet]. [cited 2021 May 21]. Available from: https://obgyn.onlinelibrary.wiley.com/doi/full/10.1002/ijgo.13035

14. Gebertsadik AW, Gebrehiwot GG, Desta AA, Ajemu KF, Berhe AA, Woldearegay TW, et al. Factors Associated With Obstetric Fistula Among Reproductive Age Women in Ethiopia, Community Based, Case Control Study [Internet]. In Review; 2020 Aug [cited 2021 May 21]. Available from: https://www.researchsquare.com/article/rs-61513/v1

15. Knowledge of obstetric fistula among prenatal clinic attendees and midwives in Mfantsiman municipality, Ghana - Azanu - 2020 - International Journal of Gynecology \&amp; Obstetrics - Wiley Online Library [Internet]. [cited 2021 May 21]. Available from: https://obgyn.onlinelibrary.wiley.com/doi/full/10.1002/ijgo.13034

16. Cowgill KD, Bishop J, Norgaard AK, Rubens CE, Gravett MG. Obstetric fistula in low-resource countries: an under-valued and under-studied problem - systematic review of its incidence, prevalence, and association with stillbirth. BMC Pregnancy Childbirth. 2015 Dec;15(1):193. 
17. Muleta M, Fantahun M, Tafesse B, Hamlin EC, Kennedy RC. Obstetric fistula in rural Ethiopia. East Afr Med J [Internet]. 2008 Mar 28 [cited 2021 May 21];84(11). Available from: http://www.ajol.info/index.php/eamj/article/view/9572

18. Mwanri L, Gatwiri GJ. Injured bodies, damaged lives: experiences and narratives of Kenyan women with obstetric fistula and Female Genital Mutilation/Cutting. Reprod Health. 2017 Dec;14(1):38.

19. Muleta M, Fantahun M, Tafesse B, Hamlin EC, Kennedy RC. Obstetric fistula in rural Ethiopia. East Afr Med J [Internet]. 2008 Mar 28 [cited 2021 May 21];84(11). Available from: http://www.ajol.info/index.php/eamj/article/view/9572

20. Jacobson LE, Marye MA, Phoutrides E, Nardos R. Provider Perspectives on Persistent Urinary Incontinence Following Obstetric Fistula Repair in Ethiopia. Front Glob Womens Health. 2020 Oct $15 ; 1: 557224$.

21. Women with obstetric fistula in Ethiopia: a 6-month follow up after surgical treatment - Browning 2008 - BJOG: An International Journal of Obstetrics \&amp; Gynaecology - Wiley Online Library [Internet]. [cited 2021 May 21]. Available from:

https://obgyn.onlinelibrary.wiley.com/doi/epdf/10.1111/j.1471-0528.2008.01900.x

22. Risk factors for obstructed labour in Eastern Uganda: A case control study [Internet]. [cited 2021 May 21]. Available from: https://journals.plos.org/plosone/article?

id $=10.1371 /$ journal.pone.0228856\#references

\section{Table}

Table 3 is not available with this version.

\section{Figures}

Figures 1 and 2 are not available with this version.

\section{Figures}




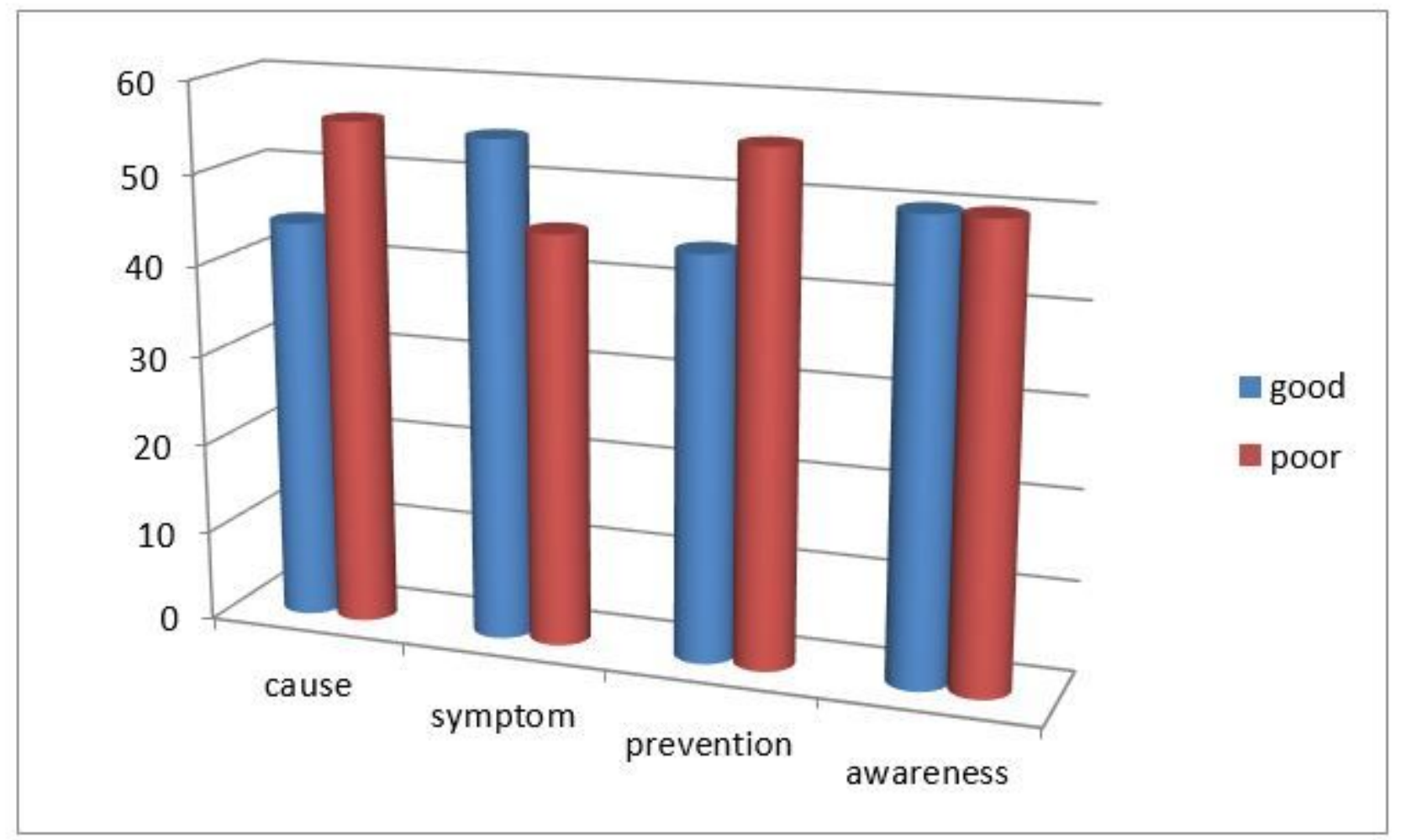

Figure 1

The status of women's awareness on obstetric fistula in in public hospitals in llubabor zone, Oromia Region, south west Ethiopia, 2021. 